\title{
"Free-hand" technique for thoracolumbar pedicle screw instrumentation: Critical appraisal of current "State-of-Art"
}

\author{
Tobias A. Mattei ${ }^{1}$, Murilo S. Meneses ${ }^{1}$, Jerônimo B. Milano ${ }^{1,2}$, Ricardo Ramina ${ }^{3}$ \\ ${ }^{1}$ Department of Neurosurgery, Instituto de Neurologia de Curitiba, ${ }^{2}$ Spine Surgeon, Instituto de Neurologia de Curitiba, ${ }^{3}$ Chief of \\ Neurosurgery, Department of Instituto de Neurologia de Curitiba, Brazil
}

\author{
Address for correspondence: \\ Dr. Tobias Mattei, \\ Department of Neurosurgery, \\ Instituto de Neurologia de Curitiba, \\ Brazil. \\ E-mail: tobiasmattei@yahoo.com
}

DOI: $10.4103 / 0028-3886.59465$

\begin{abstract}
Pedicle screws are widely used for instrumentation of the thoracolumbar spine. The anatomic studies performed in the last two decades, detailing the complex morphometry and three-dimensional anatomy of the thoracolumbar pedicles, have enabled the emergence of the so-called "free-hand" technique of pedicle screw placement based exclusively on anatomical parameters. However, in the thoracic spine, the benefits of pedicle screws have been tempered by its potential risks, such as, spinal canal violation, pedicle fracture, nerve root compression, and vascular lesions. Furthermore, the narrow and inconsistent shape of the thoracic pedicles, especially in spinal deformity, makes their placement technically challenging. In this article, the authors make a critical appraisal of current "state-of-art" of "free-hand" technieue of pedicle instrumentation, analyzing its anatomical basis, surgical technieue, present indications and limitations as well as the role of adjuvant image-guided and neurophysiological monitoring methods.
\end{abstract}

Key words: Free-hand technique, pedicle anatomy, pedicle screw instrumentation, posterior spinal fixation, thoracolumbar fractures

\section{Introduction}

The technique for pedicle screw instrumentation of the spine has gone through significant progress over the last two decades. ${ }^{[1]}$ The pedicle screws were initially used in the lumbar spine. ${ }^{[2]}$ As the surgeons have become more comfortable with the complex anatomy required for accurate screw placement, the technique for pedicle instrumentation has evolved to include their use in the thoracolumbar and thoracic levels. ${ }^{[3]}$ Besides offering an overall construct rigidity, pedicular screws have several advantages over traditional hook and rod constructs: they allow the stability necessary for spinal arthrodesis and improve deformity correction due to its three-column control over the spinal elements. Pedicle screw instrumentation also obviates the need to place instrumentation within the spinal canal thus lessens the risk of neural injury. Moreover, the placement of pedicle screws is independent of facet or laminar integrity and, thus, has been extremely useful to a varied range of spinal pathologies, such as traumatic, degenerative, oncologic, as well as deformity correction ${ }^{[4-8]}$ However, in the thoracic spine, the benefits of pedicle screws have been tempered by its potential risks, such as,: spinal canal violation, pedicle fracture, nerve root compression, and vascular lesions. Furthermore, the narrow and inconsistent shape of the thoracic pedicles, especially in spinal deformity, makes pedicle screw placement technically challenging at this level [Table 1]. ${ }^{[3]}$

\section{Surgical technique}

\section{Lumbosacral spine}

The "free-hand" technique for placement of pedicle instrumentation relies completely on the use of visible as well as palpable anatomic landmarks for accurate pedicle screw placement. It is dependent on a clear exposition and identification of the posterior elements' bony landmarks, including the lateral border of the pars interarticularis, the entire transverse process and the caudal and cephalad 
Table 1: Anatomic factors which determine the wide use of "free-hand" technique for pedicle screw placement in the thoracolumbar and lumbosacral spine as well as possible disadvantages of such technique when dealing with the upper and middle thoracic levels

\section{Thoracolumbar and lumbosacral spine}

Gold-Standard

Anterior violations less dangerous

Larger pedicle size

"Safety Zone" between T10-L4

Several anatomic and morphological studies

Lateral violations often asymptomatic

Upper and middle thoracic spine
Challenging
Adherence of thoracic viscerae to anterior longitudinal ligament
Smaller pedicle size - pedicle fracture and violations
Smaller diameter of spinal canal
Inter-Individual variability in pedicle-body angle and pedicle axis
Lateral violations dangerous to pleura, great vessels and esophagus

facet joints. In the last few years several anatomic studies have been performed to detail the complex morphometry and three-dimensional anatomy of the lumbar pedicles. ${ }^{[9-11]}$

In the lumbar spine an osteotomy (partial facetectomy of the infero-lateral one-third of the inferior articular process of the superior vertebrae is usually performed for three reasons: It enables the identification of the exact limit between the superior and inferior articular processes; it facilitates the correct identification of the ideal initial perforation site; it decreases the amount of cortical bone (which may make the initial perforation difficult, specially in the presence of hypertrophic facets); and finally it provides a smooth bony surface for final allocation of the head of the screw. The entry point is in the intersection between a line that passes just laterally to the inferior articular process and a line which bisects the transverse process. At S1, the entry point is at the infero-lateral margin of the basis of the superior articular process of the sacrum [Figure 1]. The direction of the screws follows the axis of the pedicle. It is slightly oblique towards the midline (on an average $10-15^{\circ}$ ). Its angular value is variable according to the individual. The obliquity towards the sagital plane can be preoperatively evaluated by computed tomography (CT) scan. The length of the screws in the lumbosacral region varies from $40-45 \mathrm{~mm}$ for L1 to L4, $45-50 \mathrm{~mm}$ for L5, and $35-40 \mathrm{~mm}$ for S1. After the initial perforation, internal pedicle palpation by ball tip and gearshift probe, as well as tapping, are utilized in order to verify the presence of possible pedicle violations. After the placement of pedicle screws the final construct is connected with rods, 3D heads, and loction caps.

\section{Thoracic spine}

Anatomical studies have demonstrated that, in contrast to the lumbar spine, considerable variation may exist among thoracic vertebrae, either in terms of the relationship of the transverse process and the axis of the pedicle or in the angle of the pedicle to the vertebral body. ${ }^{[12]}$ Because of the variability in these individual parameters, "free-hand" pedicle instrumentation in the upper and midthoracic spine based exclusively on anatomic landmarks may be imprecise and eventually lead to unacceptable rates of misplaced screws. In fact, both clinical and cadaveric studies have shown that about $15 \%$ to $50 \%$ of thoracic screws placed using "freehand" technique may violate the pedicular cortex. $[7,10,13]$

The optimal anatomic location for screw entry in the thoracic spine is much more difficult to determine in comparison to the lumbar level. The general rule, which places the rostro-caudal center of the pedicle at the midpoint of the transverse process, does not necessarily hold true in the widely variable thoracic spine. ${ }^{[12]}$ Not only this location is variable, as one moves from the rostral to the caudal portions of the thoracic spine, but also it is known that there might be significant segmental variability from the left to the right side. Moreover, unlike the large ovoid lumbar pedicle, the cross-sectional morphology of a single thoracic pedicle is widely variable in the coronal plane. ${ }^{[14]}$

As a rule, it could be stated that beginning in the lower thoracic spine at T10-T12, the starting point is located at the junction of a vertical line which passes along the lateral boundary of the "pars articularis" and a transverse line dividing the transverse process in its half [Figure 2]. As one moves proximally toward the the mid-thoracic spine the starting point begins to move medially. At T7-T9 the starting point is the most medial, being located along a vertical line just lateral to the midpoint of the superior articular process and a transverse line along the superior border of the transverse process [Figure 3]. As one moves more proximally from the mid-thoracic to the upper thoracic spine the starting point for screw insertion moves back more laterally. At T1-T2 the starting point is located at the intersection of a vertical line along the lateral border of the pars interarticularis and a transverse line bisecting the transverse process [Figure 4]. ${ }^{[15,16]}$

The transverse angle of the pedicle usually demonstrates, according to anatomical studies, a consistent decrease from $30^{\circ}$ convergent at $\mathrm{T} 1$ to $13.9^{\circ}$ in the fourth thoracic vertebra. ${ }^{[3]}$ The transverse angle of the pedicle between $\mathrm{T} 4$ and T9 is quite similar between $13.9^{\circ}$ in the fourth thoracic vertebra to $7^{\circ}$ in the ninth thoracic vertebra. The pedicle axis of the lower thoracic spine (T10, T11, and T12) becomes neutral to slightly divergent because the 
location of the rib head sequentially moves backward towards the base of the pedicle at T11 and T12. So even the lower thoracic pedicles provide the firm purchase of the pedicle screw from a lateral starting point and $10-15^{\circ}$ convergent angle..$^{[15]}$

The transverse pedicle diameter is the critical anatomical variable when selecting the width of the screws. Usually the lower thoracic spine (T10, T11, and T12) has the biggest pedicles varying from $6.3-7.8 \mathrm{~mm}$. The transverse pedicle diameter of the mid-thoracic pedicle from $\mathrm{T} 4$ to T9 has the smaller pedicles varying from $4.7-6.1 \mathrm{~mm}$. Usually the pedicles between T4 and T6 are the smallest while the largest is at T12. The T4 through T1 pedicles tend to become progressively larger (diameter between 5.6-7.9 mm) when moving in a cephalad direction. ${ }^{[15]}$ The ideal average length of the screws varies from $40-45 \mathrm{~mm}$ for the lower thoracic region, $35-40 \mathrm{~mm}$ for the mid thoracic region, and $30-35 \mathrm{~mm}$ for the proximal thoracic region in adolescents and most adults.

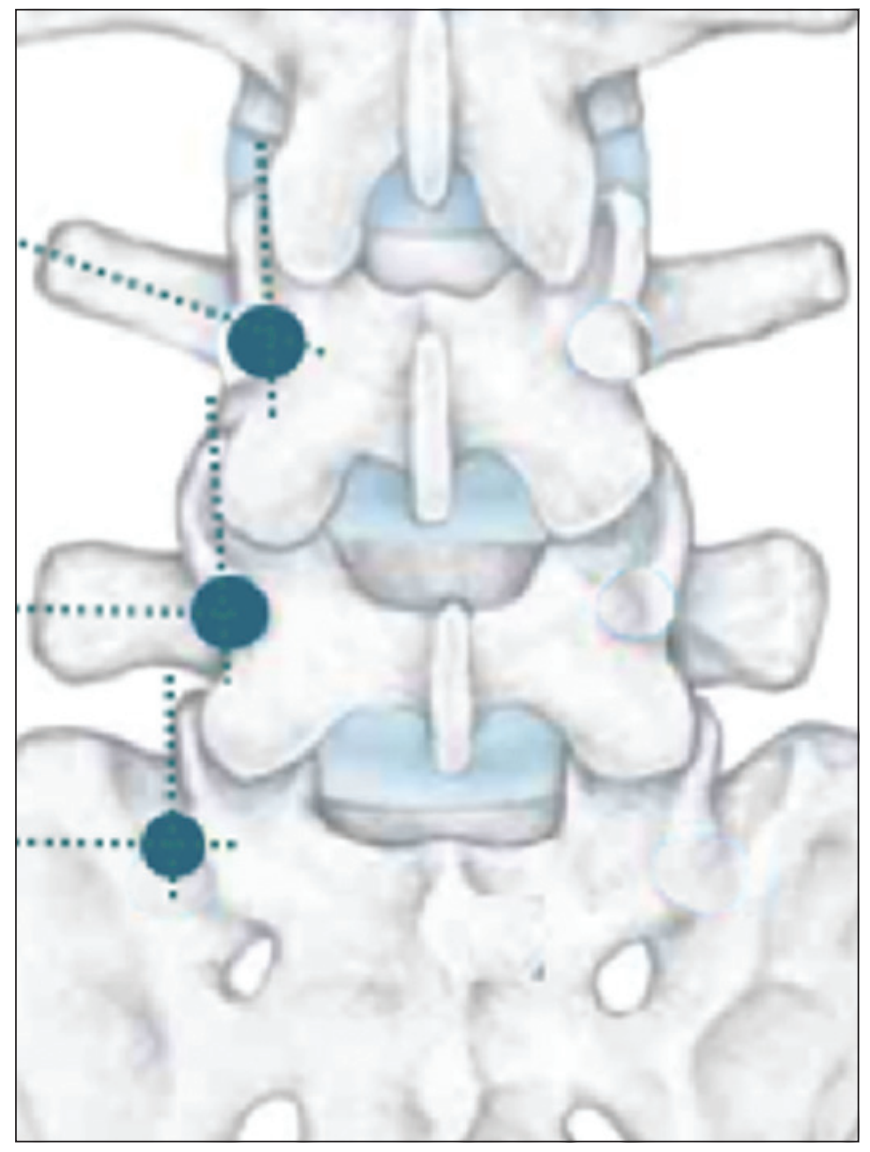

Figure 1: Entry points for pedicle screw placement in the lumbosacral spine. At the lumbar spine the entry point is in the intersection between a line that passes just laterally to the inferior articular process and a line which bisects the transverse process. An osteotomy (partial facetectomy) of the infero-lateral one-third of the inferior articular process of the superior vertebrae is usually performed. At S1 level, the entry point is at the infero-lateral margin of the basis of the superior articular process of the sacrum

\section{Postoperative evaluation methods}

In the last one decade classic studies of "free-hand" technique for pedicle screw placement have considered both CT scans and anatomic dissections as gold-standard methods for evaluating the position of pedicle screws as well as its relation to adjacent structures. ${ }^{[17]}$

Although many spine surgeons consider antero-posterior and lateral plain X-rays as adequate imaging modality for the assessment of the final positions of pedicle screws, it has been well established from late 80s that these imaging methods may lead to unacceptably high rates of false-positive and false-negative evaluations..$^{[13]}$ Moreover, "in vivo studies" in the lumbar spine have also demonstrated the superiority of CT compared to the conventional radiography in assessing violations either within the pedicle or distally at the anterior vertebral body. ${ }^{[18,19]}$ These studies suggest that "thin-slice" CT scan should be the "gold standard" method for scientific studies evaluating postoperative pedicle screw placement. Coronal reconstructions are especially useful in determining the relationship of the screw to the pedicular cortex. Importantly, it has already been demonstrated that CT scans show good correlation with the macroscopic findings in the cadaveric studies of screw placement [Figure 5]. ${ }^{[20]}$
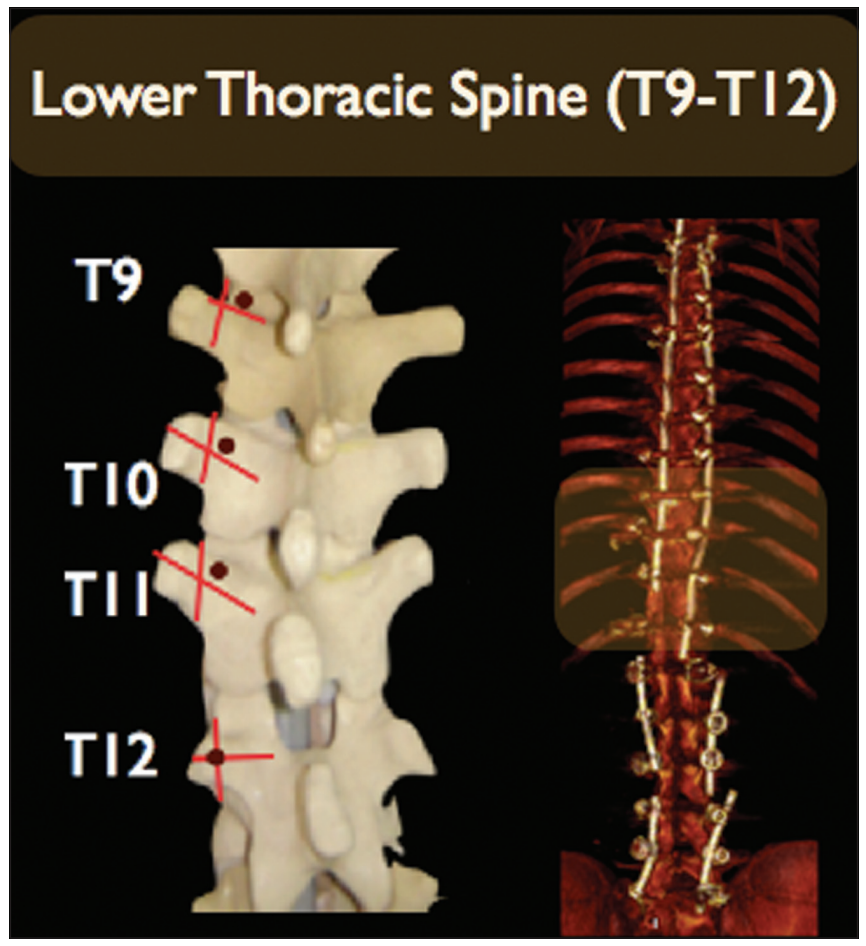

Figure 2: Superficial bony landmarks for placement of pedicular screws through the "free-hand" technique in the lower-thoracic spine (T9-T12): The entry-point is located at the junction of a line which bisects the transverse process and lamina and a vertical line just medial to the lateral aspect of pars articularis 


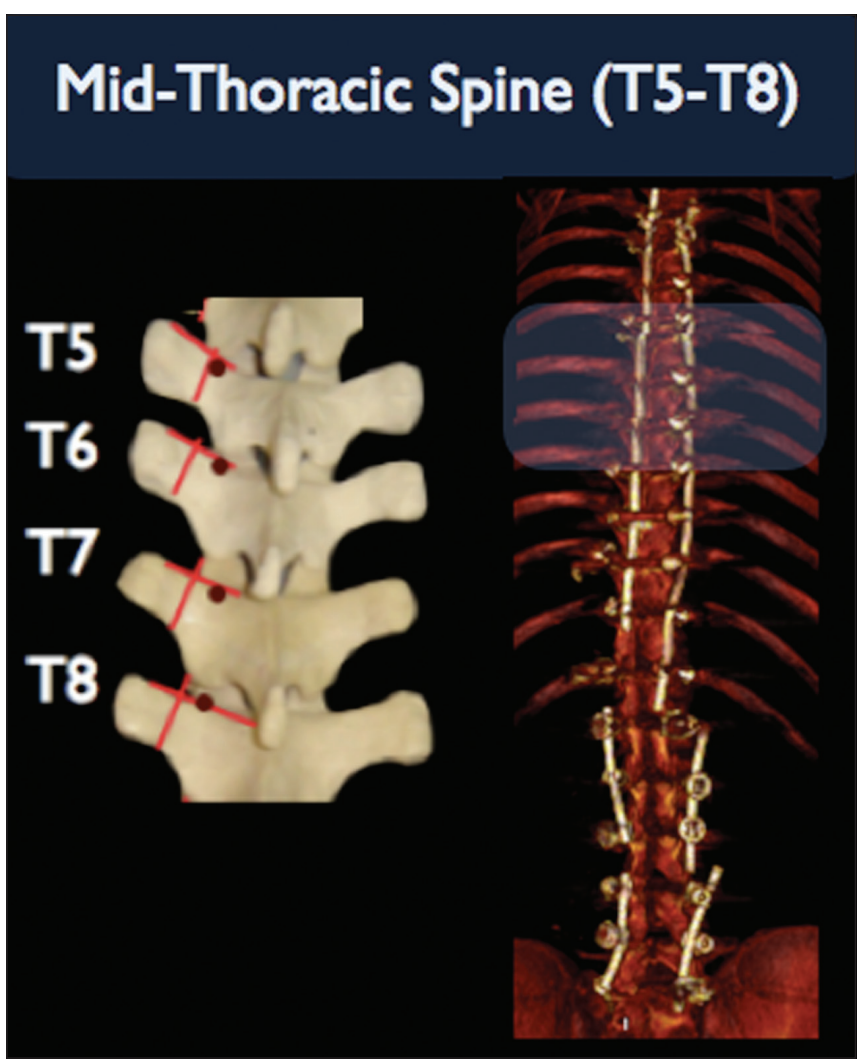

Figure 3: Superficial bony landmarks for placement of pedicular screws through the "free-hand" technique in the mid-thoracic spine (T5-T8):

The entry-point is located at the proximal edge of the transverse process and lamina, just lateral to midportion of the base of superior articular process. Note that there is a trend towards a more medial and cephalad location of the entry point as one proceeds from lower to the mid-thoracic region

\section{Pedicle violations}

The overall reported rates of correct pedicle screw placement is extremely variable in the surgical literature. ${ }^{[2,17,19,21]}$ Although there are anecdotal articles reporting "miss" rates as high as 55\% in cadaveric series of "free-hand" technique placement of pedicle screw in the thoracic spine, ${ }^{[22]}$ in the largest published clinical series to date, the reasonable rates of misplaced screws seems to be not more than $25 \%$ or $30 \% .^{[7]}$ In a classic cadaveric study of "free-hand" technique, which also included lumbar spine pedicle screw placement, the overall missing rate was $21 \%$. Interestingly, in this study, when only the thoracic spine was considered, the overall rate of pedicle screw misplacement was $18,75 \%$ only. ${ }^{[13]}$

It is still a matter of debate, but it seems that the addition of fluoroscopy modestly improves the accuracy of screw placement, especially in the upper and middle thoracic spine. ${ }^{[23]}$ However, as some authors suggest, the increased rates of radiographic cortical violations do not necessarily correlate with poorer clinical outcome. In fact, in the two largest series of thoracic pedicle screws placed with fluoroscopic guidance alone, the authors

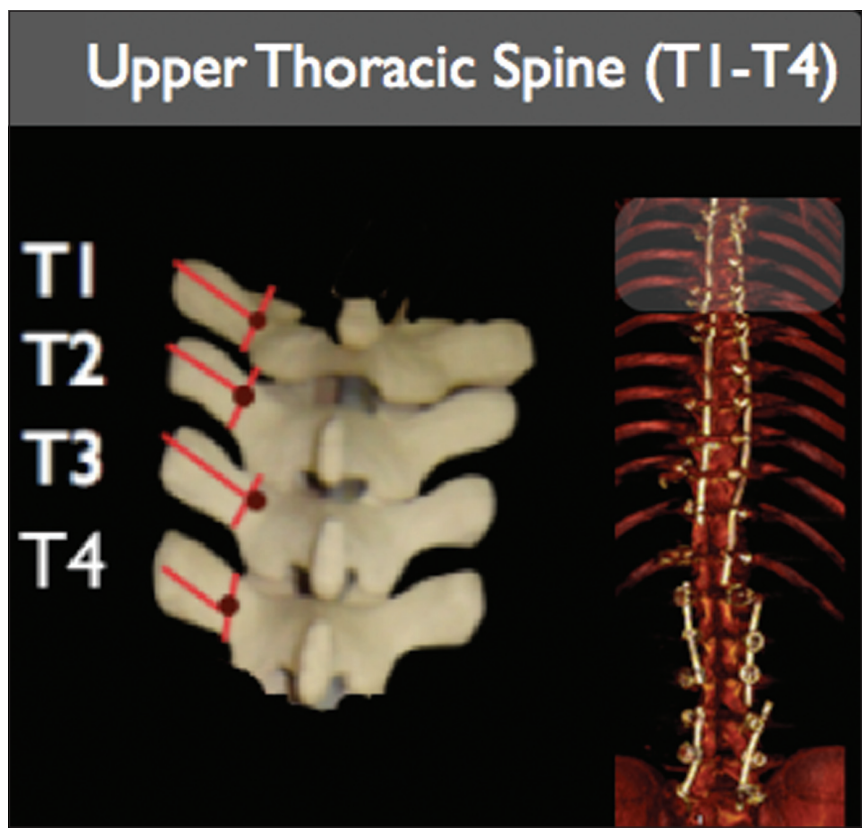

Figure 4: Superficial bony landmarks for placement of pedicular screws through the "Free-hand" technique in the upper thoracic (T1-T4): The entry-point is located at the junction of the line which bisects transverse process and a vertical line along. Note that there is a trend towards a more lateral and caudal direction as one proceeds from the mid to upper thoracic spine

noted a low incidence of neurological injury in spite of higher rates of pedicular violations. ${ }^{[7,23]}$

A classification for the evaluation of pedicle screw violations has been recently proposed:[24] Grade I Violations: Screws that replace the cortex without extending beyond the pedicular cortical margin; Grade II Violations: Screws that extend less than $2 \mathrm{~mm}$ beyond the pedicular cortex; and Grade III Violations: Screws that extend more than $2 \mathrm{~mm}$ beyond the pedicular margin. Grade III violations are further divided into "intentional lateral screw entry through the costovertebral joint" (a standard maneuver for thoracic screw placement in the presence of pedicles of small diameters) and true "anatomically significant errors" [Figure 6]. Only Grade II and Grade III screws are considered true cortical violations.

Finally, a recent anatomic study investigated whether the accuracy of "free-hand" technique of lumbar pedicle screw placement is optimized by performing a laminectomy before screw placement, with screw entry point and trajectory being guided by pedicle visualization and palpation. ${ }^{[25]}$ The results revealed that all screw placements were grossly within the confines of the pedicles, regardless of the technique, as evidenced by CT scan analysis. Additionally, both "anatomic-landmark" technique and "open laminectomy" technique yielded biomechanically equivalent pedicle screw and rodfixated constructs. From this study, it can be concluded 
that first decompressing the spinal canal (as indicated in most pathological cases in which arthrodesis is intended) and then performing the pedicle screw insertion under direct vision seems to be a rational alternative for those levels where the surgeon is not able to identify proper anatomic bony landmarks. However, up to now, there is no scientific evidence for the superiority of such "underdirect vision" technique over "free-hand" technique based exclusively on anatomical parameters.

\section{Injury}

Pedicle screw placement in the thoracic spine presents a unique challenge. Unlike the lumbar pedicle, there is little room for error in the small and three-dimensional complex thoracic pedicles. Medial errors are less forgiving in the thoracic spine because there is less mobility of the spinal cord at this level in comparison to the nerve roots in the cauda equina. Lateral perforations of the pedicular cortex are potential threats to the pleural cavity, great vessels and esophagus, mainly in the upper and middle thoracic levels [Figure 7a]. ${ }^{[26]}$ In the case of inferior violations, in the thoracic spine the most feared consequence is refractory neuropathic pain [Figure 7b], whereas in the lumbar spine injury to the emerging nerve roots may lead to unacceptable postoperative motor deficits.

The panorama radically changes when moving caudally

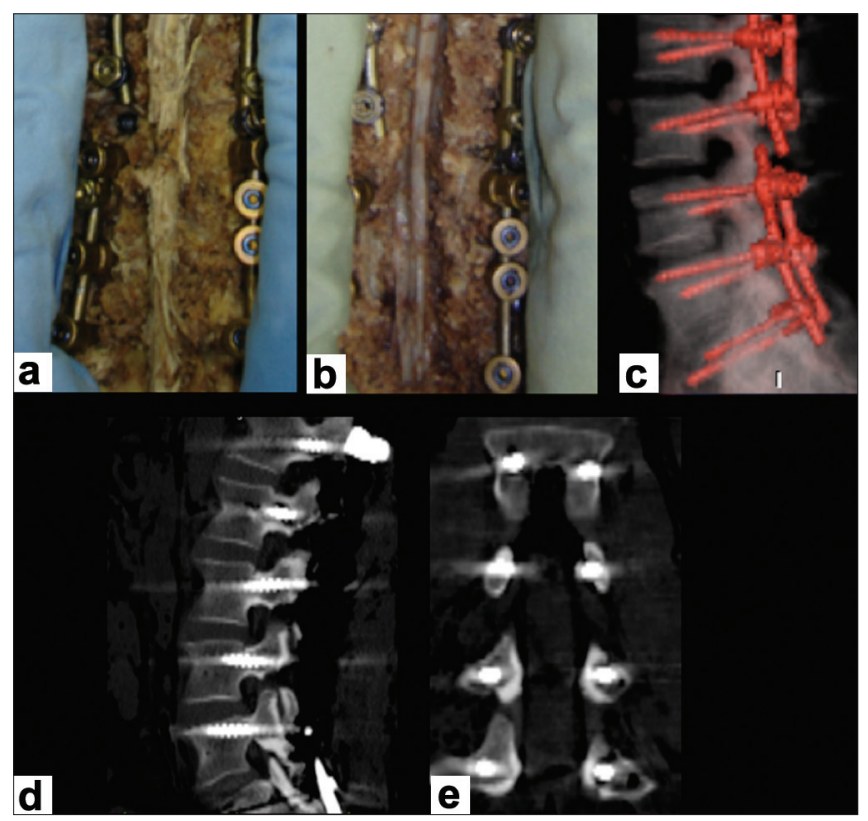

Figure 5: Photographs of an anatomic specimen after posterior midline incision, initial dissection of the paravertebral musculature and exposition of the posterior bone landmarks, pedicle screw placement (a) and further decompression of the lumbosacral spinal canal (b) in order to expose the adjacent emergent nerve roots (c). "Thin-slice" computed tomography scans show good correlation with macroscopic findings in cadaveric specimens ( $c$ and d). Coronal reconstructions are especially useful in determining the relationship of the screw to the pedicular cortex (e) from the thoracic to the thoracolumbar junction and lumbosacral spine. In a series which evaluated the rates of medial violation of the screws in the thoracolumbar transition, only patients with violations of more than $6 \mathrm{~mm}$ presented neurological deficits, suggesting that, between T10 and L4 exists a "safety zone" which tolerates medial violations up to $4 \mathrm{~mm}$. This was attributed to the larger diameter of the pedicle at this region as well as larger diameter of the spinal canal. ${ }^{[23]}$ As already mentioned, the incidence of pedicle violation reported in the literature seems to correlate inversely with the size of the pedicle. ${ }^{[21]}$ In morphometric studies, the transverse diameter of the pedicle diminishes from T1 in caudal direction, presenting the lower value at the mid thoracic region (T6 and T7). From T8 to L5, the pedicle diameter grows progressively and the rates of pedicle violation diminishes accordingly. ${ }^{[11,9]}$ Anterior violations in the lumbar spine are much less dangerous Once abdominal viscerae are usually not fixed to the anterior longitudinal ligament, except in lumbosacral transition [Figure $7 \mathrm{~b}$ ]. (The authors provide a guide of the sagital and transverse angle for safe pedicle screw insertion in Figure 8.)

\section{Assisted technologies}

In contrast to the well-established anatomic and morphological studies of the thoracolumbar pedicles, the individual variability of the upper and middle thoracic

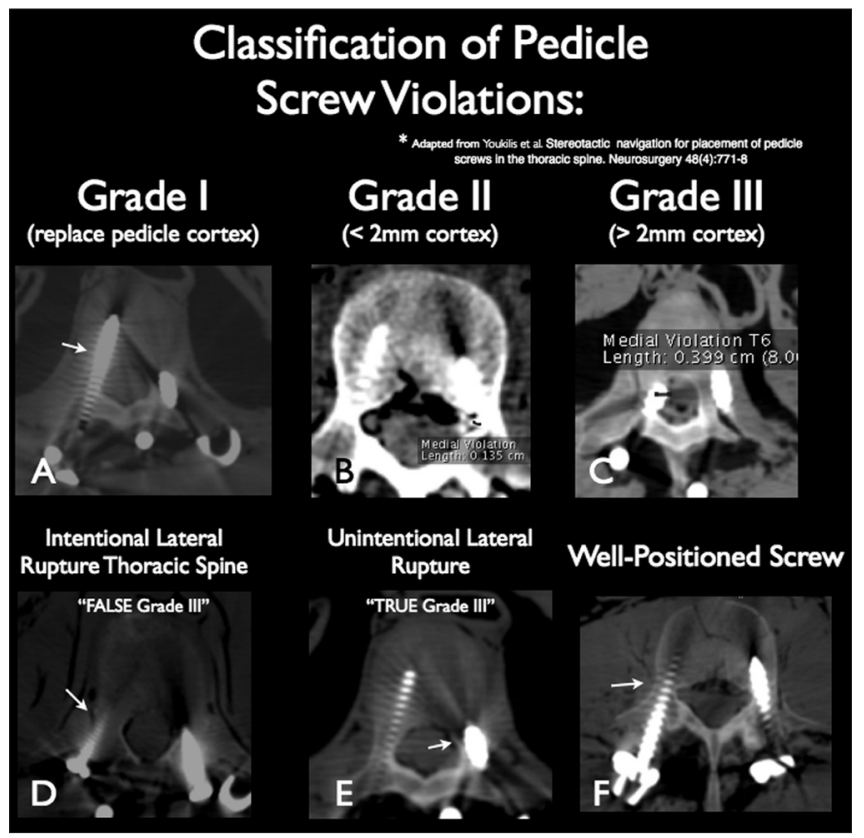

Figure 6: Classification of pedicle screw violations: (a) Grade I: These are not true violations once the screw replaced the pedicular cortex without extending beyond it; (b) Grade II: The pedicle screw extends less than $2 \mathrm{~mm}$ beyond the pedicle cortex; (c) Grade III: The pedicle screw extends more than $2 \mathrm{~mm}$ outside of the cortical margin; (d) False Grade III violations: Intentional lateral violation of the pedicle in the thoracic spine with the screwing entering through the costovertebral joint; (e) True Grade III lateral violation; (f) Pedicle screw considered to be in an acceptable position 


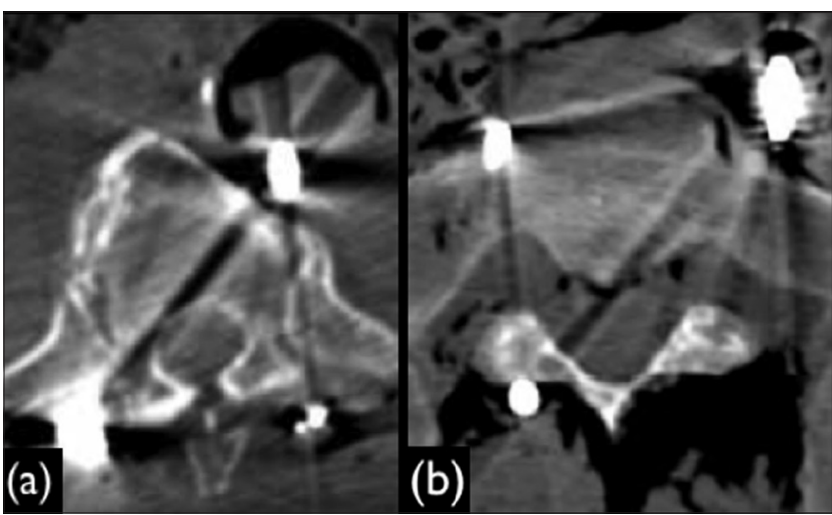

Figure 7: (a) Critical anterior violation in the thoracic spine (T6) in a cadaveric specimen: Note that the pedicle screw contacted the posterior wall of the aorta; (b): Critical anterior violation in the lumbosacral region in a cadaveric specimen: The pedicle screw touches the posterior wall of the rectum

segments of the spine among different populations has led some authors to question the safety of the "free-hand" technique for placement of pedicle screws in this region based exclusively on anatomical parameters. In order to overcome some of these problems, several adjuvant techniques for accurate localization of the pedicles have been used, such as intraoperative imaging methods and navigation. Besides that, functional techniques aiming to avoid neural injury, such as neurophysiological monitoring, have also been suggested monitoring have also been suggested. ${ }^{[24,27]}$ However, it must be highlighted that the routine use of such adjuvant techniques adds additional costs and also increases the operative time. Moreover, even those who defend the use of imageguided systems recognize that these methods rely on images obtained before surgery. Therefore, gross intrasegmental instability may preclude accurate intra-operative guidance. This clinical scenario provides two possibilities for errors. Firstly, segmental instability in the setting of severe trauma may lead to intraoperative errors in localization from the time interval of CT scan acquisition to navigation, from registration to navigation, or both. Secondly, once pedicle instrumentation is initially applied, it can move if vigorous intra-operative forces are applied in an effort to further reduce and align the spine. ${ }^{[24]}$

Besides fluoroscopy and navigation, other new adjuvant assisted-technologies, such as the electromagnetic image-guided surgery (Navitrak), has emerged as a component in the armamentarium of the so called computer-assisted orthopedic surgery (CAOS). ${ }^{[28]}$ However, apart from the high costs associated with implementation of such technologies, some studies suggest that their use benefits only novice surgeons with no statistically significant effect on the experienced surgeons. Therefore, it could be argued that it would not be advisable to learn procedures which employ all these

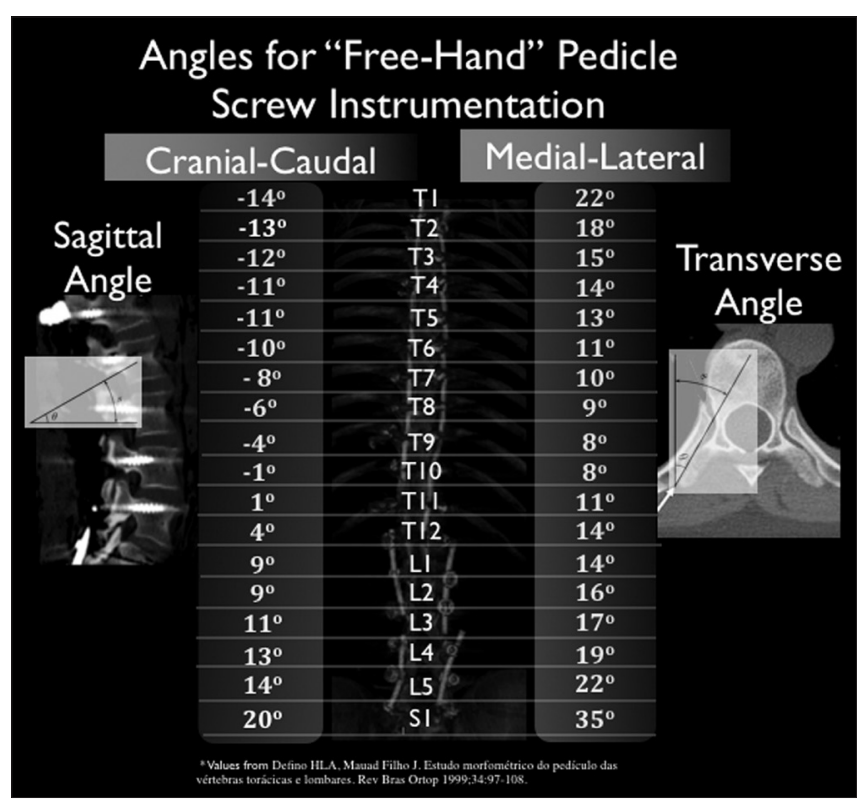

Figure 8: Sagittal (cranial-caudal) and transverse (medial-lateral) angles for pedicle screw placement in the thoracolumbar and sacral spine. The transverse angle is calculated with basis on pedicle's angle and the midline. The sagittal angle is calculated with basis in the pedicle's angle and a line parallel to the ground.

technological apparatus which would probably never be useful in real situations. ${ }^{[29]}$

A critical review on the topic has recognized that computer-assisted operations (CAOS) involve additional surgical steps which take both time and manpower: Operations usually take longer; some products require additional imaging; all systems need to have infrared beacons anchored to bone and which produce significant further morbidity and risks, besides being very expensive (for some center almost prohibitive), has almost the same size as an image intensifier, taking up space in the operating suite and requiring specialized nursing support; and finally, the software contracts associated with each system, may be exorbitant. ${ }^{[30]}$

\section{Conclusions}

The authors agree with other authorities on the issue ${ }^{[31]}$ that, in the present "state-of-art" of spine surgery, the relatively consistent anatomy, the large size of the pedicles, and the fast learning curve for "free-hand" placement of pedicle screw in the lumbar spine, makes the routine use of image-guided systems a luxury that the majority of experienced spine surgeons do not absolutely need. In fact, there is currently evidence that such "free-hand" technique of thoracolumbar and lumbosacral pedicle screw placement is reliable and safe even in cases of deformity, ${ }^{[15]}$ revision spinal surgery, and at the levels with a solid posterior fusion mass or identified pseudarthrosis, the most challenging situations because of the loss of anatomic landmarks. ${ }^{[32]}$ 
As far as the thoracic spine is concerned, specially in the upper and mid thoracic levels, the consensus is that the available adjuvant techniques like image guidance and neurophysiological monitoring may be of value in order to minimize the inherent disadvantages which make the "free-hand" screw placement in these locations imprecise. The use of the adjuvant "armamentarium" in these locations is likely to be associated with reduced rates of misplaced screws and may be cost effective.

In regard to assisted-technologies, such as CAOS, the authors' opinion is that developments in spine surgery should always be stimulated and further research in this area is welcome. However, the high costs associated with of these technologies, forbidens it to become a reality in the routine practice of most spine centers around the world. Furthermore, up to now, the constant practice and obsessive practice still remains the paramount factor for the development of high-skilled spine surgeons.

\section{Acknowledgments}

The authors manifest special gratitude to:

Synthes ${ }^{\oplus}$, that freely provided the technical support for the anatomic dissections which helped in illustrating this article.

"“Centro de Diagnóstico por Imagens" - CETAC/INC, Curitibal Brazil, which freely allowed the performance of CT scans in the anatomic specimens of our pilot study of "free-hand" thoracolumbar pedicle screw placement.

Anatomy Department of "Universidade Federal do Paraná"/Brazil, which, as part of a scientific research project, provided the cadaveric specimens for our pilot study.

\section{References}

1. Roy-Camille R, Sailant G, Mazel C. Plating of thoracic, thoracolumbar, and lumbar injuries with pedicle screw plates. Orthop Clin North Am $1986 ; 17: 147-59$.

2. Castro WH, Halm H, Jerosch J, Malms J, Steinbeck J, Blasius S. Accuracy of pedicle serew placement in lumbar vertebrae. Spine $1996 ; 21: 1320-4$.

3. Zeiller SC, Lee J, Lim M, Vaccaro AR. Posterior thoracic segmental pedicle screw instrumentation: Evolving methods of safe and effective placement. Neurol India 2005;53:458-65.

4. Fernández-Fairen M, Sala P, Ramírez H, Gil J. A prospective randomized study of unilateral versus bilateral instrumented posterolateral lumbar fusion in degenerative spondylolisthesis. Spine 2007;32:395-401.

5. Mazel C, Hoffmann E, Antonietti P, Grunenwald D, Henry M, Williams J. Posterior cervicothoracic instrumentation in spine tumors. Spine 2004;29:1246-53.

6. Lü FX, Huang Y, Zhang Q, Shi FL, Zhao DS, Hu Q. Pedicle screw fixation against burst fracture of thoracolumbar vertebrae. Chin J Traumatol 2007;10:349-52.

7. Liljenqvist UR, Halm HF, Link TM. Pedicle screw instrumentation of the thoracic spine in idiopathic scoliosis. Spine 1997;22:2239-45.

8. Boachie-Adjei O, Girardi FP, Bansal M, Rawlins BA. Safety and efficacy of pedicle screw placement for adult spinal deformity with a pedicle-probing conventional anatomic technique. J Spinal Disord 2000;13:496-500.

9. Defino HLA, Mauad Filho J. Estudo morfométrico do pedículo das vértebras torácicas e lombares. Rev Bras Ortop 1999;34:97-108.

10. Cinotti G, Gumina S, Ripani M, Postacchini F. Pedicle instrumentation in the thoracic spine. A morphometric and cadaveric study for placement of screws. Spine 1999;24:114-9.

11. Ebraheim NA, Jabaly G, Xu R, Yeasting RA. Anatomic relations of the thoracic pedicle to the adjacent neural structures. Spine 1997;22:1553-6.

12. McCormack BM, Benzel EC, Adams MS, Baldwin NG, Rupp FW, Maher DJ. Anatomy of the thoracic pedicle. Neurosurgery 1995;37:303-8.

13. Weinstein JN, Spratt KF, Spengler D, Brick C, Reid S. Spinal pedicle fixation: Reliability and validity of roentgenogram-based assessment and surgical factors on successful screw placement. Spine 1988;13:1012-8.

14. Kothe R, O'Holleran JD, Liu W, Panjabi MM. Internal architecture of the thoracic pedicle. An anatomic study. Spine 1996;21:264-70.

15. Kim YJ, Lenke LG, Bridwell KH, Cho YS, Riew KD. Free hand pedicle screw placement in the thoracic spine: Is it safe? Spine 2004;29:333-42.

16. Chung KJ, Suh SH, Desai S, Song HR. Ideal entry point for the thoracic pedicle screw during the free hand technique. Int Orthop 2008;32:657-5.

17. Vacearo AR, Rizzolo SJ, Balderston RA, Allardyce TJ, Garfin SR, Dolinskas C, et al. Placement of pedicle screws in the thoracic spine. Part II: An anatomical and radiographic assessment. J Bone Joint Surg Am 1995;77:1200-6.

18. Berlemann U, Heine P, Müller U, Stoupis C, Schwarzenbach O. Reliability of pedicle serew assessment utilizing plain radiographs versus CT reconstruction. Eur Spine J 1997;6:406-10.

19. Farber GL, Place HM, Mazur RA, Jones DE, Damiano TR. Accuracy of pedicle screw placement in lumbar fusions by plain radiographs and computed tomography. Spine 1995;20:1494-99.

20. Yoo JU, Ghanayem A, Petersilge C, Lewin J. Accuracy of using computed tomography to identify pedicle screw placement in cadaveric human lumbar spine. Spine 1997;22:2688-91.

21. de Marco FA, Risso-Neto MI, Cavali PTM, Sussi MA, Pasqualini W, Landim E, et al. Placement analysis of thoracic and lumbar pedicle screws inserted under anatomic and radioscopic parameters. Coluna/Columna 2008;7:1-7.

22. Xu R, Ebraheim NA, Ou Y, Yeasting RA. Anatomic considerations of pedicle screw placement in the thoracic spine: Roy-Camille technique versus open-lamina technique. Spine 1998;23:1065-8.

23. Gertzbein SD, Robbins SE. Accuracy of pedicular screw placement in vivo. Spine 1990;15: 11-5.

24. Youkilis AS, Quint DJ, McGillicuddy JE, Papadoupoulos SM. Stereotactic navigation for placement of pedicle screws in the thoracic spine. Neurosurgery 2001;48:771-8.

25. Karim A, Mukherjee D, Gonzalez-Cruz J, Ogden A, Smith D, Nanda A. Accuracy of pedicle serew placement for lumbar fusion using anatomic landmarks versus open laminectomy: A comparison of two surgical techniques in cadaveric specimens. Neurosurgery 2006;59:13-9.

26. Mulholland RC. Pedicle screw fixation in the spine. J Bone Joint Surg Br 1994; 76:517-9.

27. Carbone JJ, Tortolani PJ, Quartararo LG. Fluoroscopically assisted pedicle screw fixation for thoracic and thoracolumbar injuries: Technique and short-term complications. Spine 2003;28:91-7.

28. Berlemann U, Langlotz F, Langlotz U, Nolte LP. Computer-assisted orthopedic surgery. From pedicle screw insertion to further applications. Orthopade 1997;26:463-9.

29. Richards PJ, Kurta IC, Jasani V, Jones CH, Rahmatalla A, Mackenzie G, et al. Assessment of CAOS as a training model in spinal surgery: A randomised study. Eur Spine J 2007;16:239-44.

30. Sikorski JM, Chauhan S. Computer-assisted orthopaedic surgery: Do we need CAOS? J Bone Joint Surg Br 2003;85:319-23.

31. Youkilis AS, Quint DJ, McGillicuddy JE, Papadopoulos SM. Stereotactic navigation for placement of pedicle screws in the thoracic spine. Neurosurgery 2001;48:779-80.

32. Kim YW, Lenke LG, Kim YJ, Bridwell KH, Kim YB, Watanabe K, et al. Free-hand pedicle screw placement during revision spinal surgery: Analysis of 552 screws. Spine $2008 ; 10: 1141-8$.

Accepted on 02-07-2009

Source of Support: Synthes $₫$, Centro de Diagnóstico por Imagens and Anatomy Department of "Universidade Federal do Paraná"/ Brazil, Conflict of Interest: None declared. 